\title{
Schizophrenia and the Cultural Epidemiology of Stigma in Bangalore, India
}

\section{Citation}

Raguram, Ramanathan, Thubarahalli M. Raghu, Penelope Vounatsou, and Mitchell G. Weiss. 2004. "Schizophrenia and the Cultural Epidemiology of Stigma in Bangalore, India." The Journal of Nervous and Mental Disease 192 (11) (November): 734-744. doi:10.1097/01.nmd.0000144692.24993.1b.

\section{Published Version}

doi:10.1097/01.nmd.0000144692.24993.1b

\section{Permanent link}

http://nrs.harvard.edu/urn-3:HUL.InstRepos:35642608

\section{Terms of Use}

This article was downloaded from Harvard University's DASH repository, and is made available under the terms and conditions applicable to Other Posted Material, as set forth at http:// nrs.harvard.edu/urn-3:HUL.InstRepos:dash.current.terms-of-use\#LAA

\section{Share Your Story}

The Harvard community has made this article openly available.

Please share how this access benefits you. Submit a story.

\section{Accessibility}




\title{
Schizophrenia and the cultural epidemiology of stigma in Bangalore, India
}

\author{
Ramanathan Raguram, MD, MRC Psych, (1) Thubarahalli M. Raghu, MD, (1) \\ Penelope Vounatsou, PhD, (2) Mitchell G. Weiss, MD, PhD, (2) \\ In Press \\ Journal of Nervous and Mental Disease
}

May 2004

Preprint copy
Not for distribution

(1) Department of Psychiatry, National Institute of Mental Health and Neuro Sciences, Bangalore, India.

(2) Department of Public Health and Epidemiology, Swiss Tropical Institute, Basel

\section{Acknowledgements}

Research support was provided from the National Institute of Mental Health and Neuro Sciences, Bangalore. Additional support from the Swiss National Science Foundation, grant \#32-51068.97, Cultural Research for Mental Health, is gratefully acknowledged.

Key words: Schizophrenia, stigma, cultural epidemiology, cultural psychiatry 


\section{Abstract}

Illness-related stigma is a complex and important issue, and its social impact contributes to a hidden burden of many health problems. Mitigating effects of stigma is a priority for mental health policy, especially for schizophrenia. Although numerous studies document its impact on patients and their families, health studies of stigma typically regard it in global terms without adequate attention to the conceptual and practical importance of sociocultural contexts and the particular features of illness that evoke stigma. Research at a psychiatric referral center in Bangalore, India, studied the cultural epidemiology of schizophrenia and stigma in interviews with family caretakers of 60 patients, using a locally adapted EMIC interview and the PANSS. An index of 13 stigma queries based on Goffman’s (1963) formulation covered relevant aspects and proved to be internally consistent (Cronbach’s alpha=0.81). Multivariate statistical regression and qualitative analysis of narratives were used to analyze this stigma index and identify explanatory variables based on cultural patterns of distress (PD), perceived causes (PC), and prior help seeking (HS). Significant variables included suspiciousness and inappropriate sexual behaviour (PD), heredity and bad deeds (PC), and informal help seeking (HS). Prior allopathic help seeking was negatively associated with stigma. Analysis of coded text segments from respondent narratives showed how these variables were related to family-perceived stigma, with reference to marriage practices, moral meanings of schizophrenia, and ways by which effective allopathic care minimized stigma. Findings identify features of schizophrenia-related stigma in India; they contribute to comparative culture studies, and they inform practical approaches to mitigate stigma through community awareness and improved mental health services. 


\section{Schizophrenia and the cultural epidemiology of stigma}

\section{in Bangalore, India}

\section{Introduction}

The adverse social response to illness, conceptualized as stigma, has become an increasingly important topic for research, advocacy, and health policy worldwide. It is a matter of concern for patients with mental illness and other chronic conditions, as well as their families and communities in countries with diverse cultural and socioeconomic profiles. With respect to mental disorders, reducing schizophrenia-related stigma has become a priority for public mental health policy; various local, national, and international agencies and professional organizations have been attentive to the social burden of schizophrenia and have established campaigns, like that of the World Psychiatric Association, to counter illness-related stigma (Rosen et al., 2000; Sartorius, 1997). In addition to interests in the topic in Western high-income countries, where social psychologists and mental health professionals initially developed the concept of stigma and applied it to health research, recent studies have also acknowledged the importance of the topic in low- and middle-income countries (Lai and Chee, 2001; Philips et al., 2002; Suguira et al., 2001; Thara et al., 2000). Reducing stigma has been acknowledged as a global priority for population-based approaches to improving mental health (WHO, 2001).

To document its particular effects and importance, and to identify strategies to deal with it, stigma research on schizophrenia has made use of various approaches. Studies have examined public perceptions and attitudes and the impact on interpersonal behavior (Angermeyer and Matschinger, 1995); stigma scales have been administered to patients (Link et al., 1987), and qualitative accounts of stigma and schizophrenia from patients have also been considered (Wahl, 1999). In his initial formulation of stigma, Goffman (1963) recognized the importance of its effects 
on families, resulting from their association with a targeted individual, a process he called courtesy stigma. Mental health research has recently begun to consider the stigma reported by families of people with schizophrenia and other mental health problems (Angermeyer et al. 2002; Ostman and Kjellin, 2002; Phelan et al., 1998; Thara and Srinivasan, 2000).

Three approaches have been most widely employed to study stigma from this family perspective. The Family Interview Schedule (Sartorius and Janca, 1996), used in WHO’s International Study of Schizophrenia, includes 14 questions about various aspects of stigma. These are each coded on a four-point scale, which is scored additively to provide a quantitative measure of overall stigma. Qualitative features of stigma with reference to these items were not assessed (Shibre et al., 2001; Thara and Srinivasan, 2000). In studying the stigma of schizophrenia in China, Phillips and colleagues (2002) added 10 questions to the Camberwell Family Interview. Responses were recorded and post coded to make an assessment of stigma for each respondent; numeric scores, but not qualitative accounts, were reported. Schulze and Angermeyer (2002) studied qualitative accounts of stigma in three sets of focus group interviews in Germany. Unlike the previous studies, which involved families only, their focus groups also included patients and health care providers.

Needs for studies of stigma based on complementary quantitative and qualitative methods for global mental health research have also been acknowledged (Lee, 2002). Focus groups are especially effective for eliciting accounts of the range of ideas about stigma and the varieties of illness-related experience, meaning, and behavior, but other means are required to determine how stigma relates to the cultural contexts and the particular features of illness. Previous research on depression in Bangalore contributed to the development of such methods of cultural epidemiology from study of the stigma of depression in urban Bangalore (Raguram et al., 1996). Subsequent research compared stigma and depression in Bangalore and London (Weiss et al., 2001). Other 
studies used this approach to study not only stigma associated with mental health problems (Chowdhury et al., 2000; Chowdhury et al., 2001) but also infectious diseases (Vlassoff et al., 2000).

Cultural epidemiology is the study of locally valid representations of illness, which are specified by variables, descriptions, and narratives accounting for the experience of illness, its meaning, and associated illness behavior. Qualitative and quantitative research methods using the framework of locally adapted EMIC interviews provide a descriptive account, facilitate comparisons, and clarify the cultural basis of risk, course, and outcomes of practical significance to clinical practice and public health (Weiss, 2001; Weiss, 1997). Such information is especially important to guide strategies to mitigate the adverse effects and social burden of illness-related stigma. The current study applied methods of cultural epidemiology to study the stigma of schizophrenia. Locally coherent indicators of stigma were studied with reference to categories and narratives of illness-related experience, meaning, and behavior, as reported by families of patients with schizophrenia brought to a psychiatric referral center in India for treatment.

\section{Methods}

The study was conducted at the National Institute of Mental Health and Neurosciences (NIMHANS), Bangalore. Sixty patients with schizophrenia, based on ICD-10 diagnostic criteria for research (WHO, 1993), were randomly selected in the inpatient psychiatric treatment facility. After describing the study to the subjects and family caregivers, written informed consent was obtained from both.

\section{Instruments}

The pattern and severity of patients’ clinical symptoms was assessed with the Positive and Negative Symptom Scale (PANSS) (White et al., 1997). A locally adapted EMIC interview for 
$-5-$

schizophrenia was prepared and pilot tested, based on an interview that had been validated in previous studies at NIMHANS (Channabasavanna et al., 1993). This interview was administered to the principal family caregiver most directly involved in the home care and management of the patient. Both PANSS and EMIC were administered by a trained psychiatrist (TMR) on the research team.

The semi-structured EMIC interview used in this study was based on a framework for cultural epidemiology that assesses illness-related experience specified by patterns of distress (PD), the meaning of illness specified by perceived causes (PC), and help-seeking behavior (HS). The use of ethnographic methods to construct EMIC interviews and select appropriate categories has been described in previous reports (Jadhav et al., 2001; Weiss, 2001; Weiss, 1997). Patterns of distress refer to the full range of problems associated with the patient's condition. Perceived causes refer to the explanations for the occurrence of the illness. Help seeking provides a historical account of prior help seeking before the patient was brought to NIMHANS. Each section of the EMIC interview begins with open-ended queries to assess spontaneous accounts with reference to narrative and locally relevant categories. Open-ended queries are followed by probes asking about categories not previously mentioned, and in turn followed by questions eliciting a summary judgment concerning the most troubling aspect of the illness, the most important perceived cause, and the first help for the illness sought outside the home.

This EMIC interview also includes a separate section on stigma. Stigma refers to the adverse social responses to the individual and family based on identification with a disvalued health problem. Such accounts referred to either enacted or self-perceived stigma. In this study of schizophrenia, family caretakers, rather than patients themselves, were interviewed, owing to our interest in the impact of stigma on families, and the difficulty of disentangling the impact of stigma and symptoms on psychotic psychotic patients. It is necessary to specify the focus of study of 
$-6-$

stigma, inasmuch as it is not just a feature of a particular disease or disability, but inevitably situated in a web of social interactions that reflect the influence of cultural meanings (Das, 2001). Guided by theoretical concepts and prior research experience, family-perceived stigma was assessed with 13 questions concerning disclosure, experience of exclusion or rejection, blame and devaluation, diminished self-esteem, social impact on the family, and effects on marriage and ability to marry (Weiss and Ramakrishna, 2001). Each section of the EMIC interview includes both a quantitative and qualitative assessment. Narrative data for each item were preserved with verbatim accounts of the caregivers.

\section{Analysis}

We summarized the frequency of spontaneous and probed accounts of cultural epidemiological variables (categories of PD, PC, and HS) and computed their prominence for quantitative analysis of associations with indicators and a composite index of stigma. The computation of prominence combines information from several questions in a single variable, which facilitates bivariate and multivariate analysis. The computed prominence of categories of these groups of variables was based on how they were reported and respondents' subjective accounts of their significance. To compute the prominence of PD variables, illness-related problems contributed a prominence of 2 if they were emphasized and 1 if they were mentioned without emphasis. The single most troubling problem contributed an additional prominence of 3 for a total PD prominence ranging from 0 (not mentioned at all) to 5 (emphasised and most troubling).

To compute the prominence of perceived causes, those that were reported spontaneously in response to open-ended questions were distinguished from those that were reported only in response to probing queries about each particular cause on a list compiled in the course of developing and pretesting the EMIC interview instrument. Both spontaneous and probed responses were distinguished with reference to those that were emphasised or mentioned. Perceived causes 
that were emphasised spontaneously contributed a prominence of 4; they contributed a prominence of 3 if emphasised only after probing, a prominence of 2 if only mentioned spontaneously, a prominence of 1 if only mentioned after probing, and 0 prominence if not mentioned at all. The single most important perceived cause contributed a prominence of 5 , which was added to derive the total prominence of that PC variable.

Similarly, the prominence of categories of prior help seeking were computed with response to spontaneous or probed accounts, and whether used in the past year and prior to that. A category of help seeking contributed a prominence of 6 for a spontaneous report of use in the past and prior years; it received a prominence of 5 for a spontaneous report of prior use in the past year only, a prominence of 4 for a spontaneous report of prior use but not in the past year, a prominence of 3 for a probed report of use in the past and prior years, a prominence of 2 for a probed report of prior use in the past year only, and a prominence of 1 for a probed report of prior use but not in the past year. An additional prominence of 7 was added for the category identified as first help seeking apart from family, friends, or home remedies.

Grouped variables to indicate the prominence of broader concepts were computed by combining categories of individual PD, PC, and HS variables based on similar meaning. For example, marital problems, failure to marry, work problems, and so forth were grouped under the PC heading “Social causes.” The prominence of the group was computed by adding the maximum value based on the emphasis/mention and/or spontaneous probe distinctions considering all categories in that group, and adding this to the value for most troubling PD, most important PC, or first-used HS variable if any category in the group was reported as such. This overall strategy follows an approach previously developed for analysis of EMIC interview data (Weiss, 1997).

To assess stigma, responses to 13 questions were coded, yielding a four-point scale from 0 to 3, with higher values indicating a more definite indication of stigma for that item. These were 
$-8-$

combined additively with equal weight as an index of stigma. The internal consistency of all items was assessed to validate the index with the Cronbach's alpha statistic, which guided evaluation and the decision to retain or drop items of the index that was used in the subsequent analysis of stigma. This strategy is based on an approach previously developed for analysis of indicators of stigma (Raguram et al., 1996; Weiss et al., 2001).

Bivariate correlations of stigma with sample characteristics and cultural epidemiological variables specifying the prominence of PD, PC, and HS variables were assessed using the Spearman correlation coefficient for nonparametric data. Multivariate analysis was employed to correct for confounding. Only those variables related to the stigma index with a p-value for the correlation coefficient of 0.2 or less were retained in a stepwise multivariate regression model. SAS software was used for two multivariate analyses, one for individual PD, PC, and HS variables, and another for the grouped PD, PC, and HS variables. We also examined the relationship of PANSS data to the indicators and overall index of stigma.

After identifying explanatory variables that account for stigma in multivariate models, as above, narrative accounts with reference to these indicators were examined. The MAXqda qualitative software program was used to extract coded text segments clarifying the nature of stigma with reference to narrative text segments elaborating associated PD, PC, and HS variables from respective sections of the interview and data set.

\section{Results}

Study patients with ICD-10 schizophrenia included 25 men (41.7\%) and 35 women (58.3\%). The mean age ( \pm sd) of the sample was 32.8 ( \pm 11.3 ) years, ranging from 18 to 66 years, and the median age was 30. The vast majority were Hindu (93.3\%), and there were also 3 Muslims and 1 Christian. Consistent with the general clinical population presenting for treatment at 
$-9-$

NIMHANS, the mother tongue of most patients was a South Indian language, mainly Kannada (40.0\%), and also Telegu (18.3\%), Tamil (16.7\%), and Malayalam (10.0\%). All patients were fluent in Kannada, the local language of Bangalore in which they were interviewed. Nearly half the sample was married (48.3\%), and the rest had never been married (41.7\%), were separated (3.3\%), or widowed (6.7\%). More men were never married (72.0\%) than women (20.0\%, p=.002, Fisher's exact test). The most frequently reported occupational categories were unemployed for men (44.0\%) and housewife for women (57.1\%).

Responses to questions concerning various aspects of stigma are summarized in Table 1. The most frequently reported concerns about the social impact of the illness on the affected person identified difficulties for this person to marry, problems in an existing marriage, social devaluation, and avoidance by others. Other indicators suggested concerns about the social impact of the illness on the family. These included family concerns about disclosure, feelings of shame and embarrassment about their relative's condition, and difficulties for a relative of the patient to marry. Some respondents also indicted concern that the illness might have adverse effects on others.

\section{\{Insert Table 1 about here\}}

Narrative accounts of these various aspects of stigma elaborate the nature of stigma and its impact. Common themes for the social burden affecting patients and family emphasized concerns about disclosing the illness, anxieties about its impact on close relatives, and effects on marriage. Family caregiver respondents were concerned that if others knew, the patient might be made fun of, might be rejected from a joint family, might lose a job, have diminished prospects for marriage and employment, become vulnerable to violence, and subject to involuntary hospitalization. They also worried that the condition might reduce prospects of marriage for others in the family, especially girl children. People with these concerns about disclosure often tried to minimise the adverse social 
$-10-$

response by emphasising somatic symptoms. For example, the brother of a 40 -year-old farm labourer explained:

I don't want to tell anybody that he has manasika kayile (mental illness). We have told everybody that he has been suffering from tiredness and less blood (anemia). If people come to know that he has manasika kayile, nobody gives him coolie (daily wage labor) and his family suffers.

\section{Bivariate correlates of stigma}

The internal consistency of our 13-item index of stigma was good, with a value of 0.81 for Cronbach’s Alpha. Each item contributed a value from 0 to 3 to the index total; the theoretical maximum was 39, and the mean ( \pm sd) was 30.8 ( \pm 7.6$)$. Values for the sample ranged from 8 to 39, and the lower quartile, median, and upper quartile values were 26, 33, and 36 respectively.

Bivariate relationships between stigma and prominence values of categories of patients’ distress (PD) reported by relatives, perceived causes (PC), and prior help seeking (HS) are summarised in Tables 2, 3 and 4. These tables indicate significant relationships between these categories and the index of stigma ( $\mathrm{p} \leq .05)$, suggestive relationships $(\mathrm{p} \leq .1)$, and relationships of items with a p-value of .2 or less, which were retained for consideration in a multivariate regression model. Among the problems relatives reported that were associated with stigma, social disapproval, muteness and other social behavioral problems (which referred to various disorganized behaviours) had a significant bivariate association with our index of stigma. Only two people were coded for "muteness," and so the negative correlation resulting form their low stigma scores cannot be considered indicative of a general relationship.

Respondents who specified social disapproval as a feature of illness experience were concerned with “disqualification from full social acceptance,” which Goffman (1963) identified as the cardinal feature of stigma (p. 9). Such respondents feared that if their relative's problems were 
$-11-$

known, they would lose their standing in society. The brother of a patient brought for treatment explained, "We can be thrown out of the society and caste because of this." Relatives were concerned that disturbed behavior might ruin the social reputation of the family. Forty-five respondents identified disorganized behavioral problems among patterns of distress, which included various socially inappropriate activities, such as wandering and collecting rubbish, not working and sitting idly at home, abusiveness, and lack of personal hygiene.

\section{\{Insert Tables 2, 3, and 4 about here\}}

Among perceived causes, weak-minded personality had a negative bivariate association with stigma; loneliness, bad deeds, and heredity had significant positive relationships. Among categories of prior help seeking, help at home and prior visits to a healing temple had a positive bivariate association with stigma scores. The analysis of relationships between stigma scores with the ratings for positive symptoms, negative symptoms, combined positive and negative symptoms, and general psychopathology assessed by PANSS showed no relationship.

\section{Multivariate analysis of stigma}

To correct for confounding we analysed the relationship of all variables with a significant or suggestive relationship in a multivariate statistical model to identify covariates of stigma. We considered all explanatory variables with a significant or suggestive bivariate relationship $(\mathrm{p}<.2)$. Results from this analysis are summarised in Table 5 . We also considered sociodemographic sample characteristics among potential explanatory variables, but none of them remained in the model.

\section{\{Insert Table 5 about here\}}

The PD correlates of stigma emerging from the stepwise regression analysis of cultural epidemiological variables included the prominence of social disapproval, suspiciousness, sexual issues, and the category of socially inappropriate behavioral problems. Three PC variables 
remained in the model, including heredity, bad deeds, and the will of God. Among help seeking variables, only help at home remained. The statistical model accounted for $53.2 \%$ of the variance for stigma.

Considering the possibility that the PD variable for social disapproval may have been so closely related to the broader concept of stigma that it obscured the role of other variables, we examined a multivariate model excluding that explanatory variable. The resulting model, however, explained $49.5 \%$ of the variance, suggesting the explanatory power of the model was not solely reliant on that variable. This model also included the PC variable for weak-minded personality, with an inverse relationship to the stigma index, specified by a negative coefficient, but a p-value of .12 , indicating a suggestive, rather than significant, role in the model.

Narratives indicate that this may be understood as a rather mechanistic explanation. "If a person is either weak-minded or cannot solve his problems properly, he develops mental illness later by thinking excessively.” The same respondent, who emphasized weak-mindedness spontaneously and identified it as the most important perceived cause, considered this patient's condition relatively less troubling socially than other respondents (stigma index value of 23, lowest quartile): "So far people are quiet helpful. They have helped us financially, providing useful information regarding treatment places and controlling my brother whenever he is violent. I am not anticipating any problems to the family.”

The narrative accounts of the various aspects of stigma also show the nature of positive relationships of variables retained in the model to stigma. For instance, among caretakers who emphasized suspiciousness as a prominent feature of the illness, stigma was high; family considered paranoid behavior to be a source of embarrassment that made the illness difficult to conceal. "I feel ashamed when she abuses people with foul language, particularly when she abuses good people around me. I wonder why she says that people want to kill her, when they are so good 
to her.” For some, the suspiciousness disrupts social life because friends no longer wish to visit.

“My friends told me on many occasions that they don’t want to come home because my wife abuses them. They prefer meeting me outside my home.” The husband of a 37-year-old woman explained that his wife's parents did not want to visit her. "Even my in-laws have avoided her, as she also suspects them of wanting to poison her to take her property.”

Concerns about sexual issues contributed to stigma in various ways. Relatives felt ashamed when the patient speaks in a socially inappropriate way to others about sexual matters. "He tells it to people without thinking what he is speaking and without any shame, which makes me more ashamed and embarrassed.” Aware of the sexual content of problems drove some friends away and contributed to social discrimination:

One of my neighbors, who was my best friend, came home one day. She overheard my brother's conversation with me; he was explaining his problems to me, including unusual sexual experiences. I did not give much importance to the effect on her, but from the next day onwards she started avoiding me. She stopped talking with me. When I asked her about the reasons for her strange behavior, she replied, "How can brother and sister discuss sexual things?” When I told her that he has been suffering from manasika kayile, she was in a state of shock. She spread this news to all of my neighbors. I did not expect that from her.

Bad deeds, sometimes specified and sometimes not, were a frequently reported perceived cause of patients' illness associated with stigma. Among respondents who reported both, the social disapproval of the bad deed was sometimes mentioned. "There are people who equate manasika kayile with sin and bad deeds in the past. That means that we have done a lot of sin either in the past or present life. People look down upon the family members." This cultural concept of karma may also be associated with punishment and the will of God: 
I think we have done something wrong. Probably my husband who is a priest made some mistakes predicting success in marriage, and these mistakes may have broken someone's marriage. This could be the reason for our suffering, my daughter's illness, and the difficulty of getting her married. Parents suffer a lot more if one of their children suffers than they do from their own sufferings. I can say that it is all the will of God to decide what mistakes we have done and how are we punished."

The relationship between heredity and stigma was articulated with respect to two distinct themes, one focussing on social concerns and the other emphasizing concerns about transmission of the illness to the patient's children. The first considered how others would think about the family, assuming from the presence of this illness in the home that the family is socially tainted. The second theme indicated concerns about marriage based on fear that the individual with the illness would pass it to offspring. "People are afraid of her and might think that even her children may develop the same illness." Families were also concerned that relatives who themselves did not have the illness might nevertheless pass it on to their children. "I also have doubts about myself," one respondent explained, "and that is why I have not yet married."

The social vulnerability of women with respect to arranged marriages highlighted the impact of gender on stigma: "If people come to know that she has been having manasika kayile, they might refer to her as mad, which will affect the future of our other female children.” Positive personal experience, on the other hand, could mitigate such concerns. A respondent with a stigma index value of 5 , indicating very low stigma, questioned its role in complicating arrangements for marriages. "I am not very certain about this aspect, because my in-laws agreed for my marriage with their son, even after knowing that my mother is mentally ill.”

The relationship between stigma and the preference for help at home reflected a desire to keep others from knowing about the illness. In that regard, stigma motivated denial of the 
seriousness of illness and the need for timely treatment. For such patients, a period of relying exclusively on help at home was followed by use of magico-religious healers, healing temples, or Ayurveda, which further delayed help seeking from allopathic practitioners.

We just kept her at home without informing anyone about her illness. We didn't take help from anyone at all because of fear she would be labelled as a mad person. Later when she did not improve, we took her to a faith healer, thinking that some evil spirit must have possessed her. We spent a lot of money but without any improvement. We thought that she would recover from her illness one day, but her condition has worsened.

Patients were also kept at home not just to conceal the condition, but in some cases to conceal the perceived causes of the condition, which were themselves a source of shame and social disapproval. The brother of a man who identified an incestuous relationship as a prominent cause spoke of the family's desire to avoid disclosure of this aspect of the patient's condition. "We never

took him anywhere. We feared that the incestuous relationship with my sister might become known to others, and so we kept him at home only, even though we knew that he was suffering from manasika kayile, and that he needed treatment.”

\section{Grouped categories}

In a second multivariate model, instead of using the individual categories of PD, PC, and HS, we examined the explanatory role of grouped categories. (See group headings of Tables 2, 3, and 4.) The process of grouping may either clarify otherwise unapparent relationships if members of the group have a consistent, but individually insignificant, relationship with stigma; or they may obscure relationships if members of the group have in inconsistent relationship with the outcome. Although this strategy reduced the overall explanatory power of the model $(\mathrm{R}$-square $=41.4 \%)$ by obscuring some of the relationships of individual categories, it also identified the role of several 
aspects of illness experience, meaning, and behavior that were not apparent in the analysis of individual categories (Table 6).

\section{\{Insert Table 6 about here\}}

Although none of the individual categories under the heading of ingestion had a bivariate association with stigma (see Table 3), the grouped category for ingestion had a significant negative association in the multivariate analysis. The grouping amplified the negative relationships of alcohol, smoking, and abused drugs as a group, which were not observable for the individual PC categories. With reference to help seeking, no individual categories of allopathic help seeking had a significant relationship-or even a suggestive enough bivariate association with stigma to be considered in the multivariate model, but the grouped category for the various types of allopathic help seeking had a strong negative association with stigma in the multivariate model for grouped variables $(\mathrm{p}<.01$ and $\mathrm{R}$-square $=0.13)$. The nature of that relationship was elaborated in narrative accounts. For example, the parent of a patient who indicated how the appeal of an allopathic disease framework countered stigma and reluctance to disclose explained: "I have come to know that it is also a disease like diabetes or hypertension. So I think that there is no harm informing people that my son has been suffering from manasika kayile.” Recognition of the value of allopathic treatment also motivated some people to encourage others not to keep the illness a secret, so that it would not interfere with needed health care. "We have guided many people to come to NIMHANS when we noticed some psychological problems with them. I have given my mother's example to convince them to undergo treatment as early as possible if they hesitate to come to the mental hospital.”

The grouped category of informal help seeking combined consultation with friends and relatives and the category of help at home. This grouped category identified a stronger association between informal help seeking and stigma $(\mathrm{p}<.01$ and R-square $=0.15)$ than the individual HS category of help at home and the other categories of the group. 


\section{Discussion}

This study clarifies the nature of stigma as it affects families of people with schizophrenia seeking psychiatric treatment in urban India, and it shows how stigma is related to the cultural features of illness-related experience, meaning, and behavior in this group. Findings are also likely to apply more widely in India, but the validity of a suitable assessment for stigma and identification of its determinants require local validation and study. Findings contribute to both the methodology of cross-cultural research and substantive findings concerning perceived stigma of families of people with schizophrenia. The interdisciplinary methods of cultural epidemiology employ quantitative and qualitative methods to clarify the social burden of this condition. Various indicators for study of the stigma of psychiatric disorders include queries concerning concerns about disclosure, social avoidance, impact on the illness-affected person and family, and social discrimination. Findings showed that these indicators collectively comprise a coherent assessment of stigma.

Despite the absence of a local language term for stigma, our assessment was attentive to questions of cultural validity, exploring both the coherence of various indicators quantitatively and their local meaning qualitatively. The index of stigma that we used for this research was validated for internal consistency (Cronbach’s alpha $=.81$ ) and systematically elaborated qualitatively. Integrating quantitative and qualitative methods in this way confers synergistic benefits. For example, the relationship to stigma of prior help seeking choices and experience in treatment shows that culturally distinctive features of the Indian health system and options for mental health care in our study setting were related either positively (prior informal help seeking) or negatively (prior allopathic help seeking) to questions of stigma. The qualitative accounts indicate the cultural logic that explains the nature of these relationships-how informal help seeking represents and facilitates reluctance to disclose unacceptable features of illness, and how positive experience in allopathic 
care may encourage individuals and the community to seek effective help and overcome reluctance to disclose.

Previous studies of stigma and mental illness have elaborated core features of stigma (Link and Phelan 2001), examined the impact of stigma on the course of illness and recovery (Link et al., 1991), and considered the impact on adherence to treatment of depression (Sirey et al., 2001). Our research was concerned with the clinical epidemiology of stigma itself, considering the role of various clinical determinants assessed with PANSS and cultural determinants assessed with a locally adapted EMIC interview. Results of a multivariate regression found that these variables accounted for $53.2 \%$ of the variance in the index of stigma, demonstrating the substantial influence and relevance of these variables. Clinical measures (PANSS), on the other hand, were unrelated to this index of stigma. Although clinical assessment may be essential for planning appropriate treatment, inattention to social context made the clinical measures unsatisfactory indicators of social burden and patterns of social distress that constitute stigma. This finding indicates some of the limitations of standard clinical and psychiatric epidemiological assessment and the need innovative approaches to clinical approaches (such as cultural formulation) and population-based assessments of mental health problems (such as cultural epidemiology).

Our study of stigma also contribute to comparative analysis of cultures. It it notable that American accounts of stigma emphasize the role of perceived violence and dangerousness, which the U.S. Surgeon General's report identified as the single most important cause of stigma targeting mental illness (US DHHS, 1999). Our findings suggest that the association with violence may be a culture-specific feature of stigma in the United States, inasmuch as no such relationship was identified in our Indian sample. The urban South Indian cultural concept of stigma emerging from our analysis was characterized by a different set of associations, namely, social disapproval, suspiciousness, inappropriate sexual activity, and other disorganized behavior. Among categories of 
perceived causes related to stigma, we identified hereditary transmission, bad deeds in a previous life, and the Will of God. Narrative accounts of caretaker respondents explain how these explanatory variables constituted discrediting flaws, which mark the affected person as tainted in one way or another, and in a manner highly compatible with Goffman's account of spoiled identity (Goffman 1963). Consequently, as with many cross-cultural comparisons, both similarities and differences were notable.

Inasmuch as stigma may influence behavior to avoid disclosure, help-seeking correlates of stigma are matters of practical interest because they are related to a mental health policy priority to promote appropriate utilization of mental health services (Hoyt et al., 1997). Concealment of hospitalization has been regarded in some studies as a manifestation of stigma (Phelan et al., 1998). Our findings suggest that stigma motivated an effort to contain the illness within the home out of similar concerns. Families hoped the problems of the affected person would get better in time, and they chose to avoid the social disapproval anticipated from seeking help outside. Many of these patients with prominent use of informal help and high stigma also made use of magico-religious and traditional healing, which provided culturally more acceptable care and avoidance of less acceptable allopathic help seeking. These findings suggest that the levels, and perhaps the features and determinants, of family-reported stigma will differ in different help-seeking sites (e.g., patients of traditional healers or seeking help in temples and dargahs). Nichter (1981) indicates that ayurvedic practitioners in India are sensitive to patient and family concerns about the social component of illness experience, and they may emphasize somatic and cultural physiological formulations to mitigate stigma and blame.

The prominence of prior use of allopathic services was associated with less stigma. Those who used such mental health services were either less influenced by stigma at the outset, or their experience with allopathic treatment mitigated stigma, or both. Furthermore, inasmuch as 
respondent accounts showed that experience in the course of prior allopathic treatment also provided a means of controlling socially disruptive behaviors, which were regarded as stigmatizing, the effectiveness of interventions lent credibility to an allopathic disease model of schizophrenia. This also mitigated stigma reported in the EMIC interviews. This finding supports the agenda of professional mental health societies (such as the World Psychiatric Association's initiative) to reduce stigma by promoting awareness, competence, and availability of mental health services.

\section{Conclusion}

This study confirms the importance of stigma, identifies its determinants, elaborates cultural dynamics, and discusses practical implications of stigma affecting families of persons with schizophrenia in Bangalore, India. Findings indicate the value of integrated quantitative and qualitative methods, and should inform culturally sensitive clinical practice and mental health

policy. Findings should be relevant in similar cultural and clinical settings and should also motivate comparable studies. It is hoped that this report and the methods described may be useful to clinicians, policymakers, and other investigators concerned with stigma and mental health, and with cross-cultural research. 


\section{Reference List}

Angermeyer MC, Holzinger A, Matschinger H, Stengler-Wenzke K (2002) Depression and quality of life: results of a follow-up study. International Journal of Social Psychiatry. 48(3):189-99.

Angermeyer MC, Matschinger H (1995) Violent attacks on public figures by persons suffering from psychiatric disorders. Their effect on the social distance towards the mentally ill. European Archives of Psychiatry \& Clinical Neuroscience 245(3):159-64.

Channabasavanna SM, Raguram R, Weiss MG, Parvathavardhini R, Thriveni M. Ethnography of psychiatric illness: a pilot study (1993) NIMHANS Journal 11(1):1-10.

Chowdhury AN, Sanyal D, Dutta SK, Banerjee S, De R, Bhatacharya K, Palit S, Bhattacharya P, Mondal RK, Weiss MG (2000) Stigma and mental illness: Pilot study of laypersons and health care providers with the EMIC in rural West Bengal, India. International Journal of Medicine 7:257-260.

Chowdhury AN, Sanyal D, Dutta SK, De R, Banerjee S, Bhattacharya K, Palit S, Bhattacharya P, Mondal RK, Weiss MG (2001) Prominence of symptoms and level of stigma among depressed patients in Calcutta. Journal of the Indian Medical Association 99:20-23.

Das V. (2001). Stigma, Contagion, Defect: Issues in the Anthropology of Public Health.

Background conference paper for "Stigma and Global Health: Developing a Research Agenda," 5-7 September 2001, Fogarty International Centre, Bethesda, MD. Proceedings. http://www.stigmaconference.nih.gov/FinalDasPaper.htm.

Goffman E (1963) Stigma: Notes on the Management of Spoiled Identity. Englewood Cliffs, NJ: Prentice Hall.

Hoyt DR, Conger RD, Valde JG, and Weihs K. (1997). Psychological distress and help seeking in rural America. Am J Community Psychology 25(4):449-470. 
Jadhav S, Weiss MG, Littlewood R. (2001). Cultural experience of depression among white Britons in London. Anthropology and Medicine 8(1):47-69.

Lai YM, Hong CP, Chee CY (2001) Stigma of mental illness. Singapore Medical Journal 42(3):111-4.

Lee S (2002) Socio-cultural and global health perspectives for the development of future psychiatric diagnostic systems. Psychopathology 35(2-3):152-157.

Link BG, Cullen FT, Frank J, Wozniak J (1987) The social rejection of ex-mental patients: understanding why labels matter. Am J Sociol 92:1461-1500.

Link BG, Mirotznik J, Cullen FT (1991) The effectiveness of stigma coping orientations: can negative consequences of mental illness labeling be avoided? Journal of Health \& Social Behavior 32(3):302-20.

Link BG, Phelan JC (2001) Conceptualizing stigma. Ann Rev Sociol 27:363-385.

Nichter M. (1981) Negotiations of the illness experience: Ayurvedic therapy and the psychosocial dimension of illness. Culture, Medicine and Psychiatry 5:5-24.

Ostman M, Kjellin L (2002) Stigma by association: psychological factors in relatives of people with mental illness. Br J Psychiatry 181:494-498.

Phelan JC, Bromet EJ, Link BG (1998) Psychiatric illness and fmaily stigma. Schizophrenia Bulletin 24:115-126.

Phillips MR, Pearson V, Li F, Xu M, Yang L (2002) Stigma and expressed emotion: a study of people with schizophrenia and their family members in China. British Journal of Psychiatry 181:488-93.

Raguram R, Weiss MG, Channabasavanna SM, Devins GM (1996) Stigma, depression, and somatization in South India. American Journal of Psychiatry 153(8):1043-9. 
Rosen A, Walter G, Casey D, Hocking B (2000) Combatting psychiatric stigma: an overview of contemporary initiatives. Australian Psychiatry 8(1):19-26.

Sartorius N (1997) Fighting scizophrenia and its stigma: a new World Psychiatric Association educational programme. Br J Psychiatry 170:297.

Sartorius N, Janca A (1996) Psychiatric assessment instruments developed by the World Health Organization. Social Psychiatry \& Psychiatric Epidemiology 31(2):55-69.

Shibre T, Negash A, Kullgren G, Kebede D, Alem A, Fekadu A, Fekadu D, Madhin G, Jacobsson L (2001) Perception of stigma among family members of individuals with schizophrenia and major affective disorders in rural Ethiopia. Social Psychiatry \& Psychiatric Epidemiology 36(6):299-303.

Sirey JA, Bruce ML, Alexopoulos GS, Perlick DA, Friedman SJ, Meyers BS (2001) Stigma as a barrier to recovery: Perceived stigma and patient-rated severity of illness as predictors of antidepressant drug adherence. Psychiatric Services 52(12):1615-20.

Thara R, Srinivasan TN (2000) How stigmatising is schizophrenia in India? Journal of Social Psychiatry. 46(2):135-41.

U.S. Department of Health and Human Services (US DHHS) (1999) Mental Health: A Report of the Surgeon General. Washington, DC, US Department of Health and Human Services.

Vlassoff C, Weiss MG, Ovuga EBL, Eneanya C; Nwel PT, Babalola SS, Awedoba AK, Theophilus B, Cofie P, Shetabi P (2000) Gender and the stigma of onchocercal skin disease in Africa. Soc Sci Med 50(10):1353-1368.

Wahl OF (1999) Mental health consumers' experience of stigma. Schizophrenia Bulletin 25(3):467-478.

Weiss MG (2001) Cultural epidemiology: introduction and overview. Anthropology and Medicine $8(1): 5-29$. 
Weiss MG (1997) Explanatory Model Interview Catalogue: Framework for comparative study of illness experience. Transcultural Psychiatry 34(2):235-263.

Weiss MG, Jadhav S, Raguram R, Vounatsou P, Littlewood R (2001) Psychiatric stigma across cultures: local validation in Bangalore and London. Anthropology and Medicine 8(1):71-87.

Weiss MG, Ramakrishna J (2001) Stigma interventions and research for international health. Background conference paper for "Stigma and Global Health: Developing a Research Agenda," 5-7 September 2001, Fogarty International Centre, Bethesda, MD. Proceedings. http://www.stigmaconference.nih.gov/FinalWeissPaper.htm

White L, Harvey PD, Opler L, Lindenmayer JP (1997) Empirical assessment ofthe factorial structure of clinical symptoms in schizophrenia. A multisite, multimodel evaluation of the factorial structure ofthe Postivie and Negative Syndrome Scale. The PANSS Study Group. Psychopathology 30(5):263-274.

World Health Organization (2001) Mental Health: New Understanding, New Hope. World Health Report, 2001. Geneva: World Health Organization.

World Health Organization (1993) The ICD-10 Classificationof Mental and Behavioural Disorders: Diagnostic Criteria for Research. Geneva: World Health Organization. 
Table 1. Items queried as indicators of stigma (\%)

\begin{tabular}{|l|r|r|r|r|}
\hline \multirow{2}{*}{ Item } & \multicolumn{4}{|c|}{ Total (N=60) } \\
\cline { 2 - 5 } & \multicolumn{1}{|c|}{ Yes } & \multicolumn{1}{c|}{ Pos } & \multicolumn{1}{c|}{ Unc } & \multicolumn{1}{c|}{ No } \\
\hline 1.Keep others from knowing if possible & 95.0 & 0.0 & 0.0 & 5.0 \\
\hline 2.Think less of yourself because of this person's problem & 68.3 & 3.3 & 1.7 & 26.7 \\
\hline 3. Shame or embarrassment & 91.7 & 1.7 & 0.0 & 6.7 \\
\hline 4. Others would think less of the person & 70.0 & 5.0 & 1.7 & 23.3 \\
\hline 5. Problem would have adverse effect on others & 38.3 & 10.0 & 5.0 & 46.7 \\
\hline 6. Others have avoided this person & 50.0 & 1.7 & 10.0 & 38.3 \\
\hline 7. Others might refuse to visit your home & 61.7 & 3.3 & 1.7 & 33.3 \\
\hline 8. Others would think less of the family & 70.0 & 0.0 & 15.0 & 15.0 \\
\hline 9. This condition would cause problems for family & 68.3 & 6.7 & 8.3 & 16.7 \\
\hline 10. Family concern about disclosure & 95.0 & 0.0 & 0.0 & 5.0 \\
\hline 11. Problem for this person to marry & 98.3 & 0.0 & 0.0 & 1.7 \\
\hline 12. Problem in an ongoing marriage & 95.0 & 1.7 & 3.3 & 0.0 \\
\hline 13. Problem for relative to marry & 86.7 & 3.3 & 3.3 & 6.7 \\
\hline
\end{tabular}


Table 2. Bivariate relationship of stigma and categories of distress reported by relatives

\begin{tabular}{ccc}
\hline Problems reported & $\begin{array}{c}\text { Spearman } \\
(\boldsymbol{\rho})\end{array}$ & P-Value \\
\hline Somatic & $\mathbf{0 . 0 9}$ & $\mathbf{0 . 4 9}$ \\
\hline Fatigue \& weakness & 0.13 & 0.32 \\
Physical pain & 0.23 & 0.08 \\
Other somatic problem & 0.04 & 0.76 \\
Mood & $\mathbf{0 . 0 6}$ & $\mathbf{0 . 6 7}$ \\
\hline Sadness & 0.04 & 0.74 \\
Overly exuberant & 0.13 & 0.33 \\
Non-Psychotic & $-\mathbf{0 . 0 3}$ & $\mathbf{0 . 8 2}$ \\
\hline Anxiousness & 0.22 & 0.10 \\
Fear \& avoidance & -0.10 & 0.46 \\
Difficulty concentrating & 0.06 & 0.63 \\
Mute & -0.29 & $0.03 * *$ \\
Compulsive behaviour & -0.01 & 0.94 \\
Panic & 0.00 & 1.00 \\
Vegetative & $-\mathbf{0 . 1 2}$ & $\mathbf{0 . 3 5}$ \\
Disturbed sleep & -0.12 & 0.38 \\
Disturbed appetite & -0.07 & 0.58 \\
Inappropriate sexual behavior & 0.17 & $0.20 * * *$ \\
Psychotic & $-\mathbf{0 . 0 4}$ & $\mathbf{0 . 7 4}$ \\
Strange ideas & -0.04 & 0.78 \\
Hearing voices & -0.03 & 0.85 \\
Suspiciousness & 0.24 & $0.06 * *$ \\
Miscellaneous & $\mathbf{0 . 0 0}$ & $\mathbf{0 . 9 9}$ \\
Emotionally sensitive & 0.11 & 0.38 \\
Disturbed sense of self & 0.07 & 0.60 \\
Social isolation & 0.09 & 0.48 \\
Social disapproval & 0.46 & $0.00 *$ \\
Irritability \& hostility & -0.07 & 0.62 \\
Substance abuse & 0.03 & 0.81 \\
Self-harm & 0.03 & 0.84 \\
Dangerousness & 0.05 & 0.72 \\
Disorganized behavior & $\mathbf{0 . 2 9}$ & $\mathbf{0 . 0 2} *$ \\
Cannot say & $0.02 *$ \\
& $0.14 * * *$ \\
\hline
\end{tabular}

*Significant $(\mathrm{p} \leq 0.05)$

$* *$ Borderline significant $(0.05<\mathrm{p} \leq 0.10)$

$* * *$ Not significant but retained for consideration in statistical model $(0.10<\mathrm{p} \leq 0.20)$ 
Table 3. Bivariate relationship of stigma and perceived causes

\begin{tabular}{|c|c|c|}
\hline \multirow{2}{*}{\begin{tabular}{|l} 
Perceived Causes \\
Ingestion
\end{tabular}} & \multicolumn{2}{|c|}{$\begin{array}{c}\text { Spearman P-Value } \\
(\rho)\end{array}$} \\
\hline & -0.20 & 0.13 *** \\
\hline Food/water & 0.15 & 0.25 \\
\hline Alcohol & -0.07 & 0.59 \\
\hline Smoking & -0.12 & 0.36 \\
\hline Abused drug & -0.02 & 0.90 \\
\hline Prescribed medication & 0.03 & 0.83 \\
\hline Health-IIIness-Injury & -0.04 & 0.76 \\
\hline Injury-accident & -0.03 & 0.84 \\
\hline Prior illness & -0.03 & 0.84 \\
\hline Prior treatment & 0.06 & 0.63 \\
\hline Pregnancy-childbirth & -0.03 & 0.81 \\
\hline Anatomical-physical & 0.10 & 0.45 \\
\hline Weakness-Nerves & -0.02 & 0.87 \\
\hline Weakness & 0.04 & 0.73 \\
\hline Nerves & 0.00 & 0.98 \\
\hline Family Stress & 0.22 & 0.09 ** \\
\hline Family problem & 0.08 & 0.56 \\
\hline Marital problem & -0.02 & 0.90 \\
\hline Failure to marry & 0.08 & 0.57 \\
\hline Other Stress & -0.02 & 0.87 \\
\hline Work problems & -0.10 & 0.44 \\
\hline Other interpersonal & 0.01 & 0.92 \\
\hline Bereavement & 0.10 & 0.43 \\
\hline Financial stress & 0.03 & 0.80 \\
\hline Miscellaneous stress & -0.10 & 0.45 \\
\hline Emotional & 0.09 & 0.49 \\
\hline Weak-minded personality & -0.33 & $0.01 *$ \\
\hline Worries & 0.22 & $0.08 * *$ \\
\hline Loneliness & 0.31 & $0.02 *$ \\
\hline Victimization-Abuse & -0.14 & 0.30 \\
\hline Physical abuse-adult & 0.00 & 1.00 \\
\hline Sexual abuse-adult & 0.03 & 0.80 \\
\hline Child abuse-sexual & -0.10 & 0.49 \\
\hline Child abuse-physical & -0.07 & 0.59 \\
\hline Child abuse-psychol & -0.16 & 0.22 \\
\hline
\end{tabular}

\begin{tabular}{|c|c|c|}
\hline \multirow{2}{*}{\begin{tabular}{|l|} 
Perceived Causes \\
Sexual-Reproductive \\
\end{tabular}} & \multicolumn{2}{|c|}{$\begin{array}{c}\text { Spearman P-Value } \\
(\rho)\end{array}$} \\
\hline & 0.20 & $0.12 * *$ \\
\hline Semen-vaginal discharge & 0.21 & $0.11 * * *$ \\
\hline Masturbation & 0.20 & $0.13 * * *$ \\
\hline Sexual experience & 0.23 & $0.08 * *$ \\
\hline Sexual identity & 0.14 & 0.28 \\
\hline Karma-Deed-Heredity & 0.28 & 0.03 \\
\hline Fate, chance & 0.21 & $0.11 * * *$ \\
\hline Bad deeds & 0.41 & $0.00 *$ \\
\hline Heredity & 0.37 & $0.00 *$ \\
\hline Will of god & 0.18 & $0.17 * * *$ \\
\hline Magico-Religious & 0.19 & $0.15 * * *$ \\
\hline Evil eye & 0.06 & 0.62 \\
\hline Sorcery & 0.02 & 0.90 \\
\hline Posession & 0.08 & 0.52 \\
\hline Neglect of vows \& rituals & 0.22 & $0.09 * *$ \\
\hline Astrology & 0.21 & $0.10 * *$ \\
\hline Other supernatural & 0.19 & $0.15 * * *$ \\
\hline Traditional & 0.08 & $0.56 * *$ \\
\hline Heat-cold in body & 0.11 & 0.41 \\
\hline $\begin{array}{l}\text { Vat, pitt, or kaph (wind, } \\
\text { bile, phlegm) }\end{array}$ & 0.11 & 0.39 \\
\hline Environment-Sanitation & 0.16 & 0.23 \\
\hline Environmental pollution & 0.09 & 0.50 \\
\hline Climate (hot-cold) & 0.10 & 0.45 \\
\hline Sanitation & -0.05 & 0.69 \\
\hline Personal hygiene & 0.19 & $0.14 * * *$ \\
\hline Germs-infection & 0.05 & 0.73 \\
\hline Contamination & -0.09 & 0.51 \\
\hline Other & 0.08 & 0.55 \\
\hline Other & 0.08 & 0.55 \\
\hline \multicolumn{3}{|c|}{$\begin{array}{l}* \text { Significant }(\mathrm{p} \leq 0.05) \\
* * \text { Borderline significant }(0.05<\mathrm{p} \leq 0.10) \\
* * * \text { Not significant but retained for consideration in } \\
\text { statistical model }(0.10<\mathrm{p} \leq 0.20)\end{array}$} \\
\hline
\end{tabular}


Table 4. Bivariate relationship of stigma and prior help seeking

\begin{tabular}{lccc}
\hline Help Seeking & Spearman $(\boldsymbol{\rho})$ P-Value & \\
\hline Informal & $\mathbf{0 . 3 3}$ & $\mathbf{0 . 0 1}$ & $*$ \\
Help at home & 0.33 & 0.01 & $*$ \\
Relatives/friends & 0.09 & 0.49 & \\
Drugstore & $-\mathbf{0 . 2 1}$ & $\mathbf{0 . 1 1}$ & $* *$ \\
Drugstore-pharmacy & -0.21 & 0.11 & $* *$ \\
Allopathic & $\mathbf{- 0 . 3 8}$ & $\mathbf{0 . 0 0}$ & $*$ \\
Pub allopath-general & -0.13 & 0.32 & \\
Pub allopath-psychiatry & 0.03 & 0.80 & \\
Priv allopath-general & -0.09 & 0.51 & \\
Priv allopath-psychiatry & -0.15 & 0.24 & \\
Traditional & $\mathbf{0 . 0 2}$ & $\mathbf{0 . 8 6}$ & \\
Ayurved & 0.04 & 0.75 & \\
Siddha & 0.01 & 0.97 & \\
Homeopath & 0.13 & 0.30 & \\
Magico-Religious & $\mathbf{0 . 3 8}$ & $\mathbf{0 . 0 0}$ & $*$ \\
Faith healer & 0.15 & 0.27 & \\
Healing temple & 0.31 & 0.02 & $*$ \\
Yoga & $\mathbf{0 . 0 5}$ & $\mathbf{0 . 7 3}$ & \\
Yoga & 0.05 & 0.73 & \\
Other & $\mathbf{0 . 1 1}$ & $\mathbf{0 . 4 0}$ & \\
\hline Other & 0.11 & 0.40 & \\
\hline
\end{tabular}

*Significant $(\mathrm{p} \leq 0.05)$

$* *$ Borderline significant $(0.05<\mathrm{p} \leq 0.10)$

$* * *$ Not significant but retained for consideration in statistical model $(0.10<\mathrm{p} \leq 0.20)$ 
Table 5. Multivariate analysis of stigma with reference to cultural epidemiological variables, as assessed.*

\begin{tabular}{lrrrr}
\hline Variable & Coefficient & F-Test Value & p-Value & Partial $\mathbf{R}^{2}$ \\
\hline Social disapproval (PD) & 2.43 & 4.36 & 0.04 & 0.19 \\
Suspiciousness (PD) & 3.00 & 8.81 & $<0.01$ & 0.08 \\
Heredity (PC) & 1.37 & 5.75 & 0.02 & 0.08 \\
Inappropriate sexual & 2.89 & 5.64 & 0.02 & 0.05 \\
behavior (PD) & 0.78 & 2.58 & 0.11 & 0.05 \\
Disorganized behavior (PD) & 0.74 & 3.04 & 0.09 & 0.03 \\
Help at home (HS) & 0.60 & 3.10 & 0.08 & 0.02 \\
Will of God (PC) & 1.03 & 4.11 & 0.05 & 0.02 \\
Bad deeds (PC) & & & Model R $:$ & $53.2 \%$
\end{tabular}

*Categories specifying patterns of distress (PD), perceived causes (PC), and prior help seeking (HS).

Table 6. Multivariate statistical model with reference to grouped cultural epidemiological variables*

\begin{tabular}{lrrrr}
\hline VARIABLE & Coefficient & F-Test Value & p-Value & Partial R \\
\hline Informal help (HS) & 1.70 & 16.09 & $<0.01$ & 0.15 \\
Allopathic help (HS) & -0.91 & 17.71 & $<0.01$ & 0.13 \\
Karma-deed-heredity (PC) & 1.05 & 6.62 & 0.01 & 0.10 \\
Ingestion (PC) & -0.83 & 3.66 & 0.06 & 0.04 \\
\hline & & & Model R & $41.4 \%$
\end{tabular}

*Categories specifying patterns of distress (PD), perceived causes (PC), and prior help seeking (HS). 